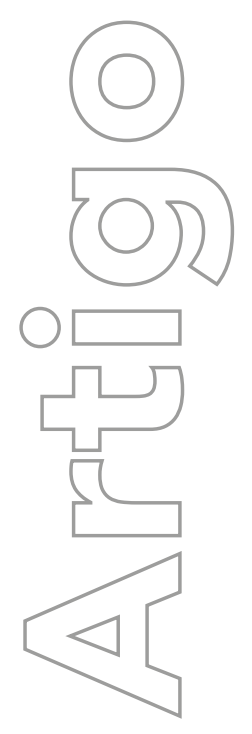

\title{
Dimensões do geográfico: da quantidade à qualidade, do ente ao ser
}

\author{
Elvio Rodrigues Martins \\ Universidade de São Paulo \\ São Paulo, SP, Brasil \\ e-mail: elmartins@usp.br
}

revista

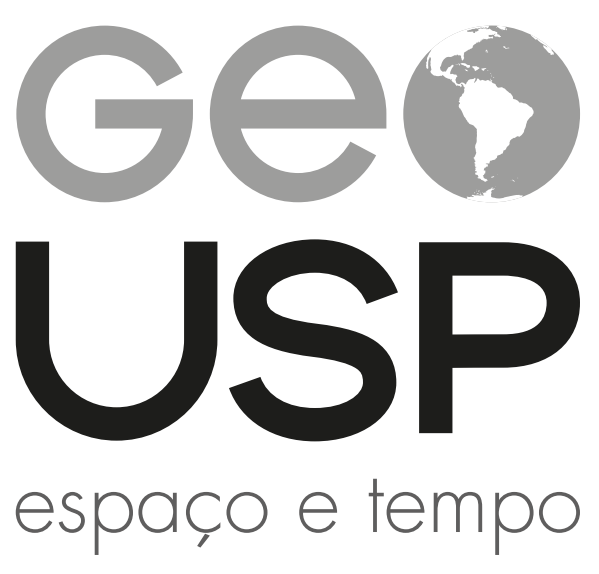

Volume $24 \cdot n^{\circ} 1(2020)$

ISSN 2179-0892 p. $8-26$

Como citar este artigo:

MARTINS, E. R. Dimensões do geográfico: da quantidade à qualidade, do ente ao ser. Geousp - Espaço e Tempo (On-line), v. 24, n. 1, p. 8-26, abr. 2020. ISSN 2179-0892. Disponível em: https://www.revistas.usp.br/geousp/article/ view/151300. doi: https://doi.org/10.11606/issn.2179-0892. geousp.2020.151300.

\section{(c) $\underset{\mathrm{BY}}{\mathrm{BY}}$}

Este artigo está licenciado sob a Creative Commons Attribution 4.0 Licence 


\title{
Dimensões do geográfico: da quantidade à qualidade, do ente ao ser
}

\section{Resumo}

Este texto é a continuação do trabalho intitulado "As dimensões do geográfico: um diálogo com Armando Corrêa da Silva". Nesta segunda parte, procuramos avançar no problema lógico e ontológico identificado por Silva na ciência geográfica, denominado impasse aristotélico-kantiano. Há aqui uma proposta de sistematização do discurso geográfico articulando suas diferentes categorias e considerando os problemas de lógica frente às dimensões espaço-temporais.

Palavras-chave: Espaço. Tempo. Lugar. Território. Região. Habitat.

\section{The geographic dimensions: from quantity to quality, from entity to be}

\begin{abstract}
This paper is a continuation of the article entitled "The dimensions of geographic: a dialogue with Armando Correa da Silva". In this second part we seek to advance the logical and ontological problem identified by Silva present in geographical science, called Aristotelian-Kantian impasse. Here there is a proposal to systematize the geographical discourse, articulating their different categories, considering the logical problems facing the space and time dimensions.
\end{abstract}

Keywords: Space. Time. Place. Territory. Region. Habitat. 


\section{Dimensiones geográficas: de cantidad a calidad, del ente al ser}

\section{Resumen}

Este texto es una continuación del trabajo titulado "Las dimensiones de lo geográfico: un diálogo con Armando Corrêa da Silva". En esta segunda parte buscamos avanzar en el problema lógico y ontológico identificado por Silva presente en la ciencia geográfica, llamado impasse aristotélico-kantiano. Aquí hay una propuesta para sistematizar el discurso geográfico, articulando sus diferentes categorías, considerando los problemas de la lógica en relación con las dimensiones espacio-temporales.

Palabras clave: Espacio. Tiempo. Lugar. Territorio. Región. Hábitat.

Este texto pode ser considerado a continuação do trabalho intitulado "As dimensões do geográfico: um diálogo com Armando Corrêa da Silva" (Martins, 2014). Aqui, procuramos avançar no problema lógico e ontológico identificado por Armando Corrêa da Silva na ciência geográfica, denominado impasse aristotélico-kantiano. ${ }^{1}$

Em termos breves, retomemos que o impasse remete ao fato de que a ciência geográfica está presa à lógica aristotélica (lógica formal) e a concepção de espaço derivada de Kant. Silva chega a essa conclusão observando que, do ponto de vista lógico formal, na ciência geográfica, o espaço é a dimensão universal; o lugar, uma dimensão particular; a área, a região, o território, dimensões singulares. Portanto, segundo o autor, a reflexão sugere que, na ciência geográfica o universal, o particular e o singular têm essa conotação categorial. Por esse caminho, chegar-se-ia à suposição de que o espaço contém o lugar, e este contém a área, a região e o território, assim como a área, a região e o território expressariam o lugar, e este, o espaço.

Nunca é demais lembrar que, para Silva (1986a, p. 28):

O conjunto de categorias de uma ciência está relacionado ao objeto de conhecimento desta ciência. As categorias fundamentais do conhecimento geográfico são, entre outras, espaço, lugar, área, região, território, paisagem e população, que definem o objeto da geografia em seu relacionamento.

Uma afirmação que se aceita implica não eleger uma única categoria como objeto da ciência geográfica. Hoje, é recorrente dar ao espaço essa condição de objeto da disciplina,

1 Pode-se acompanhar essa questão em Silva (1986c). 
bem ao gosto, por exemplo, de Milton Santos. Em outras circunstâncias, essa prerrogativa foi dada a outras categorias. A região teve um dia esse papel, como bem observam Mendoza, Jiménez e Cantero (1982), ao afirmar que a noção de região foi considerada o ingrediente primordial do pensamento geográfico chamado "clássico". Pretendeu-se ver na geografia regional a essência definitiva do fazer da ciência geográfica. Em outras circunstâncias, esse papel foi exercido pela paisagem, e nesse caso um exemplo clássico é o trabalho de Carl Troll (1982), segundo quem a geografia trataria dos diferentes fenômenos sobre a superfície da terra (litosfera, hidrosfera, atmosfera, biosfera) tomados em sua inter-relação funcional em unidades específicas, que em síntese resultariam em paisagens determinadas. Mais recentemente, vemos essa importância dada à paisagem por Jean-Marc Besse (2006), entre outros. Poderíamos ainda mencionar o destaque que alguns dão ao território, ou ao lugar, mas, passado ou presente, uma categoria parece sempre ser a escolhida para tornar-se o objeto da disciplina. E, portanto, algo distinto do afirmado por Silva, para quem a totalidade das categorias da ciência geográfica em sua relação definiriam esse objeto. Se seguíssemos essa orientação de Silva, qual seria esse objeto? O que resultaria da relação dessas categorias que encontraria na ciência geográfica seu campo de estudo?

Alguns poderiam argumentar que todas as categorias - região, paisagem, território, lugar, enfim - são na verdade o próprio espaço com outros nomes. Será? Não teria cada uma dessas categorias um sentido distinto? Não seria cada uma dimensão específica? Se sim, seriam dimensões específicas de quê?

Não querendo tornar as coisas mais difíceis, acrescentaríamos outras categorias à lista que comporia o essencial do pensamento geográfico. Somaríamos o habitat, a duração, a sucessão, o ritmo, a ligação, a relação e o movimento. E podemos deixar a lista aberta a eventuais aditamentos. Teremos um conjunto de categorias de natureza tópica (topia) e outro conjunto de ordem crônica (cronos), além de categorias referentes à interação entre partes e a própria categoria movimento dando conta da finitude da realidade.

Antes de apresentar uma resposta às questões acima, falemos um pouco sobre o significado do que vem a ser categoria. Em princípio, categoria seria qualquer noção que sirva como regra para a investigação e a correspondente expressão linguística. Mas isso é muito pouco. Procurando respeitar o que na história da filosofia encontramos sobre o tema, corremos o risco de afirmar que há duas possibilidades para o significado de categoria: uma de ordem lógica e outra de ordem ontológica. A primeira estaria relacionada à designação dos chamados gêneros supremos. A situação toda parece estar entre o disposto por Platão e Aristóteles e por meio deles ao longo da história da filosofia. Sem entrar em detalhes, a situação se desenharia na predominância desses gêneros supremos na definição da realidade, os quais também servem para entendermos essa mesma realidade. Haveria uma correspondência entre a realidade e a organização do pensamento, sendo que esta precede a forma como entendemos a realidade. Por esse caminho, chegamos à lógica formal. As categorias seriam os modos pelos quais o ser se predica como quantidade, qualidade, tempo, posição.

A outra forma de encarar as categorias remete à necessidade de distinguir ente e ser. As categorias estariam ligadas às formas elementares da existência dos entes. Seriam suas 
características predicativas, mas não seriam adjetivas do ser desses entes. Por exemplo, antes de um cavalo estar localizado (e aqui a categoria é a localização), ele precisa ser cavalo. $\bigcirc$ mesmo vale para o cavalo pesado, grande etc. É claro que alguém poderia dizer que um ente é seu ser constituído por seus predicados, mas aqui aparece um resíduo em que algo tem que ser antes de se predicar, ou, por outra, sujeito e objeto não se confundem com seus respectivos predicados, ou, então, a existência não é o mesmo que a essência, e nem o ente é o mesmo que o ser. As categorias estariam então relacionadas ao ente e diriam respeito a sua existência; já o conceito, ou mesmo a ideia estaria relacionada ao ser desses entes.

É provável que categorias científicas estejam mais afeitas à primeira proposição, reservando-se a supor categorias como participantes de uma taxionomia que ordena a realidade, no estilo gênero, número e espécie, como é visto na biologia. Ou então caminhariam na definição do ser pelos predicados do ente. Um cavalo é um mamífero, vertebrado, dotado de quatro patas, veloz e forte, e isso definiria o ser do ente cavalo, ou o que é cavalo. Mamífero, vertebrado são categorias do cavalo. Se trocarmos o cavalo pelo homem, veremos como a ciência busca a definição do homem. Hábitos e costumes, ou decodificação do genoma definiriam o que é o homem. Certas posições na filosofia diriam que esta proposição da ciência não chega nunca ao ser do homem, ficariam sempre na órbita do ente. Mas, deixemos a filosofia por hora e voltemos a geografia.

E então façamos a pergunta: as categorias geográficas seriam categorias de que ente? Em que circunstância se cria a exigência de perfilar as categorias região, paisagem, espaço etc.? Para responder, propomos desviar o olhar. Se indagamos por que o pensamento se constitui com essas categorias, devemos saber o que põe essa exigência ao pensamento ou, melhor, ao sujeito. $\bigcirc$ olhar deve se voltar para a realidade, para o objeto, ou, mais exatamente, na relação entre sujeito e objeto. E, assim, na relação sujeito-objeto, devemos encontrar a resposta.

Exploremos um exemplo. A região é categoria de quê ou de quem? $\bigcirc$ que nos dizem as teorias da região? Segundo essas teorias, as regiões se estabelecem sempre na interação entre homem e meio, entre sociedade e natureza. De um jeito ou de outro. Mesmo as regiões definidas por funções, ou fluxos, são o resultado dessas relações mencionadas, dado que fluxos e funções são fenômenos que tem por base essas relações. Ainda que a relação sociedade-natureza não seja o mesmo que a relação homem-meio, ambas envolvem apropriação, ambas competem a relação sujeito-objeto. Indagar o que é sociedade, não tem como resposta o mesmo de quem indaga o que é homem. $\bigcirc$ mesmo vale para natureza e meio. Talvez o certo mesmo fosse dizer que uma geografia de caráter regional é definida por essas relações entre sociedade e natureza, entre homem e meio, sendo que tais relações não ocorrem de forma homogênea em toda a geografia construída. Cumpre observar que a geografia de que se trata aqui não é a disciplina ou a ciência geográfica, mas algo presente na realidade, insuprimível a esta como fruto da relação entre sociedade e natureza. $\bigcirc$ nome que se dê é o de menos, mas o fato é que essa propriedade acompanha a realidade humana. Por esse caminho, podemos dizer que a geografia determinada é decorrente de uma interação específica entre sociedade e natureza e, em determinadas situações, ela assume um perfil regional. Ou, por outra, a região é categoria da geografia produzida pela relação entre sociedade e natureza. Então parece que temos a possibilidade de resposta. 
A região é categoria da geografia, como provavelmente deverá sê-lo o território, o espaço, a paisagem, o habitat, o lugar etc.

$\mathrm{E}$, assim, temos que essa relação entre sociedade e natureza deve trazer consigo sempre a produção de uma geografia. ${ }^{2}$ E essa mesma geografia agora também representa a reprodução dessa relação. Sim, porque a geografia agora se estabelece como meio de reprodução da sociedade em todos os seus aspectos, entre os quais, suas formas de reprodução material. E isso também permite a condição do estar de todos os entes. Tudo estará localizado e distribuído. Esse processo de re-apropriação do que já foi produzido torna possível a continuidade de relação com a natureza e redefine permanentemente a geografia produzida.

Agora, se olharmos com o viés da filosofia, temos que o homem como sujeito e a natureza como objeto estão inseridos nessa relação, e ambos são frutos dessa relação. Podemos concluir, portanto, que tanto o sujeito como o objeto têm uma geografia, ou seja, existiria uma geografia do objeto, e nela o homem está na condição de ente (trata-se das condições objetivas de seu existir), e existiria uma geografia pensada (ou um pensamento geográfico, ou uma consciência geográfica). Nessa condição, podemos falar num sujeito geográfico tendo como objeto a geografia do objeto. Apenas apontamos aqui que existe uma importância enorme entre a consciência geografia e a geografia como condição objetiva da existência. Os problemas do ensino de geografia estão relacionados com esta última afirmação. ${ }^{3}$

Assim, podemos agora responder de forma mais firme à pergunta acerca da proposição de Silva, de que a totalidade das categorias da ciência geográfica em sua relação definiriam esse objeto. Se seguirmos essa orientação de Silva, qual seria esse objeto? Esse objeto tem nome? $\bigcirc$ que resultaria da relação entre essas categorias? $\bigcirc$ que surge é a própria Geografia. Não, claro a ciência geográfica, mas a realidade em sua constituição têmporo-espacial. $\bigcirc$ quadro se completa quando dizemos que tanto o objeto quanto o sujeito têm uma geografia. E isso pode ser observado dentro de uma condição insuprimível do homem e da totalidade dos entes que o cercam e de que ele se ocupa. Foi o que observou Heidegger (2012, p. 107), com a espacialidade fática do Desein:

A espacialidade que a ocupação se impõe possui faticamente seus distanciamentos, entre os quais estão: distante demais, próximo de, atravessando a rua, em meio à cozinha, a dois passos, atrás da catedral, entre outros. Nessa espacialidade reside a familiaridade ocasional em suas referências, as quais sempre pertencem a ocupação.

2 Muitas vezes, perdemos de vista essa relação entre sociedade e natureza. Mas basta pensarmos em política mineral, matriz energética, manejo sustentável, por exemplo, para estar diante dessa relação. Isso para mencionar os exemplos mais evidentes. Sociedades que têm por base a geografia urbana intensificaram exponencialmente essa relação. E o paradoxo (que não é de somenos importância) é que, justamente nessas condições, perdemos de vista essa reação.

3 Poderíamos supor que essa reflexão daria a ideia de uma separação entre homem e natureza. Mas vejamos: o homem como ente pertence ao mundo genérico dos entes materiais, porém ganha particularidade na medida que torna consciente para si sua relação com os outros entes, fazendo de sua própria relação um objeto. É nesse momento que se quebra o caráter abstrato, genérico, na medida em que os entes em geral são definidos durante a práxis, ganhando com isso a condição do que são. Mediante a interação do homem com outros homens, portanto, como um ente social, e destes com o universo de entes em geral, temos a realização da práxis mediante o trabalho e, com ela, a definição do ser social e seu mundo correspondente. 
Mas Heidegger tem seus limites, e tudo acaba nessa constatação, sem explorar a profundidade que ela implica. Mesmo considerando o "ocupar-se" e a ordem tópica dos entes e seus significados, para esse filósofo, essa ordem não faz o percurso até a geografia, reduzindo-se a uma espécie de corologia fenomenológica.

Feitas essas considerações, resta apresentar uma posição que permita observar essa relação entre as categorias do pensamento geográfico.

Da diversidade de entes constitutivos do mundo, o acento é posto na relação, como o aspecto fundante e determinante da unicidade do mundo em sua multiplicidade constituinte. Há uma rica ilustração a esse respeito:

Ora, se só conheço as coisas pelas suas relações comigo e com outras, é claro que a essência delas também só será revelada por essas mesmas relações. E se há relações que me dão conta das mudanças e outras que me informam das qualidades ou atributos que se conservam através do tempo, é evidente que, pelas primeiras, sei como os seres se transformam e vem a ser o que não eram, e, pelas segundas, fico sabendo o que neles permanece a despeito das mutações, permitindo que cada qual continue a ser o que é (Andrade, 1971, p. 537).

caráter das conexões entre os entes ou entre as partes, portanto, é fundamental. Nem sempre esta complexidade infinita e multiforme, apresenta em todos os seus aspectos ligações de mesma natureza. A tendência tem sido considerar todas as conexões entre partes de caráter contraditório. As coisas não são bem assim. Nas injunções das diferentes partes em suas qualidades distintas, as conexões demonstram naturezas distintas, que nem sempre se apresentam como contradição. Na verdade, as conexões podem ser vistas sob dois aspectos. Uma relativa ao ente, e nisso definimos as contraposições. A outra conexão diz respeito ao ser, e aí sim temos as contradições.

Na verdade, é possível admitir uma ampla ligação entre as partes constitutivas do real, ou simplesmente um complexo de entes contrapostos entre si constituindo o mundo. É possível admitir também que, sob certos aspectos, os entes podem estar em relativo isolamento e, ao mesmo tempo, mantendo ligações com outros entes. Porém, o certo é que não há entes completamente isolados. É necessário que se reconheça a importância das ligações de contraposição, uma vez que nenhum ente se estabelece a partir de si mesmo, ou seja, suas ligações de contraposição lhe são fundamentais no existir. E isso pode ser dito independentemente da observação do sujeito, ou seja, trata-se de um existir indiferente a nós. E, por estar nessa circunstância de indiferença, não é possível falar em dimensão ontológica, e, sim, somente ôntica. Em síntese, todos os entes dependem para existir de suas ligações de contraposição, e isso redunda na sua dimensão ôntica indiferente a nós. Entretanto, aos nos relacionarmos com essa trama complexa de contraposições, mediante a práxis, damos o necessário conteúdo histórico ao mundo, na medida em que estabelecemos mediante nossa relação a dimensão ontológica. Na relação do homem com os demais entes, sua condição de ente intramundano, mediante essa relação de apropriação, em que a relação sujeito-objeto se processa, se constitui o ser, se faz presente o sentido. Enfatizemos: é a relação, e não o sujeito ou objeto, a protagonista do ser. É aqui que a 
transcendência se manifesta e onde tem vigência a contradição, posto que a relação do homem frente ao mundo sempre é de transcendência em relação a este. Ou seja, há a possibilidade da negação, superar o que o mundo é, levá-lo a outra condição de ser.

A relação implica a diferença/identidade entre sujeito e objeto, entre homem e meio. E toda relação é uma determinação. E toda determinação é uma negação. E isso se justifica na medida em que identidade e diferença participam da relação, ou seja, ontologicamente, o meio é a partir do seu não-ser que se encontra no homem; e o homem é a partir do seu não-ser que é o meio. $\bigcirc$ homem se faz a si mediante a construção do meio. Nada pode ser dito do homem sem sua negatividade ontológica, isto é, o meio (é como se disséssemos que nós somos nossas criações). $\bigcirc$ que se observa nestes juízos é que sem seu meio o homem não se faz homem. E quando destacarmos a geografia desse meio, observaremos o quando o estar (que representa localização e é a condição insuprimível do existir) é fundamental para o homem ser. É como se homem se fizesse homem a partir do meio que ele constrói e pertence. Mais que na condição de ente contraposto a outros entes constitutivo do meio, o homem aí se insere contraditoriamente, e assim se abre para a transcendência.

Portanto, o contexto da negatividade não é estático. Eis a transcendência, o devir. $\bigcirc$ meio constituído por uma estrutura de entes contrapostos. E essa é a estrutura do real, uma estrutura processual. A construção leva a identidade entre construtor e o construído, mas não é identidade morta. No contexto dessa relação se instaura sempre o novo.

Essa referência a uma estrutura de caráter processual justifica-se pela preocupação de não tomá-la como algo rígido e estático, mas em sua potencialidade negativa, o que implica um pensar aberto a novas injunções determinantes que venham a compor a estrutura. Ou seja, essa abertura implica considerar a desestrutura como momento em que as partes conhecem novos condicionamentos. Da mesma forma, é absolutamente necessário não tomar tais estruturas em si mesmas como elementos determinantes do movimento, mas como expressão do jogo de contraposições/determinações próprias à realidade do mundo em geral.

Uma ordem de contraposições que se posta em determinado momento como uma estrutura determinada, mas que se reorienta mediante uma nova composição das partes em ligação ou o acréscimo de novos elementos determinantes. As partes que se afirmam em-si mediante a relação de determinação/contraposição com outras partes. Numa palavra: estamos diante da ordem do real, da coexistência dos entes. Por isso chama-se espaço. Portanto, vislumbram-se os primeiros elementos que compõem a geograficidade do mundo: a relação e o espaço.

Mas é preciso que reescrevamos o que foi afirmado agora à luz da geografia. Aquilo que Leibniz teria escrito sobre espaço, agora vamos tomar em sentido mais amplo:

Quando a mim, deixei assentado mais de uma vez que, a meu ver, o espaço é algo puramente relativo, como o tempo; a saber, na ordem das coexistências, como o tempo na ordem das sucessões. De fato, o espaço assinala em termos de possibilidade uma ordem das coisas que existem ao mesmo tempo, enquanto existem em conjunto, sem entrar em seu modo de existir. E quando se vêem muitas coisas juntas, percebe-se essa ordem das coisas entre si (Leibniz, 1983, p. 177). 
Diferentemente de Leibniz, vamos considerar essa ordem como pertencente ao modo de existir dos entes. A coexistência das coisas implica uma ordem. Essa ordem é uma ordem de contraposições entre os entes e de contraposição e contradição em relação ao homem. O que abre a possibilidade de relações de negação. E, sendo assim, trata-se de um contexto de determinações.

Ou seja, a compreensão da totalidade solicita a necessidade de verificarmos sua essência em perpétua construção, mediante a consideração de que sua estrutura implica uma ordem de determinações de caráter topológico distinto, assim como uma cronologia diversa. A Totalidade, portanto, implica essas considerações distintas no tocante a sua essência: uma hierarquia de determinações estabelecida em diferentes níveis e momentos.

Espaço e tempo postam-se, assim, como categorias de existência do real e medida do ordenamento lógico do pensamento. E suas explicitações implicam vê-los, espaço e tempo, como categorias que falam das coexistências de entes localizados e distribuídos e das sucessões e, assim sendo, das relações e, portanto, da contraposição, da contradição, da negação, da determinação. E esses quatro elementos (contradição, contraposição, determinação, negação) são responsáveis pela instabilidade ôntica e ontológica da realidade. Tudo está em alguma medida se modificando, ou seja, em movimento.

Um movimento que não se reduz ao comportamento quantitativo dos entes, como uma distância percorrida que medimos em metros. Pelas necessidades epistemológicas do pensamento científico, vamos atrás sempre de medidas quantitativas da realidade. Por essa porta entra a matemática como instrumento precioso de entendimento. Para ilustrar com um exemplo, uma pessoa não pode ser conhecida no que ela é apenas por seus números (altura, pressão arterial, idade e todo tipo de coeficiente conhecido). Há muito mais em jogo. Observar a realidade do ponto de vista quantitativo é observar seu comportamento fenomênico que se permite verificar quantitativamente. Porém, nem tudo é possível nestes termos. Além de aspectos fenomênicos não quantificáveis, há ainda aspectos essenciais correspondentes a tais fenômenos. A qualidade está relacionada a este segundo caso. Certas propriedades qualitativas não são mensuráveis quantitativamente, e é exatamente aqui que a ciência se detém e a filosofia continua. Nos entes, a rigor, a qualidade não se permite ver analiticamente, mas apenas em termos de uma síntese resultante. Tomemos a nós mesmo como exemplo. Cada indivíduo é um todo, e neste todo reside sua qualidade, sua possibilidade de ser.

E há ainda as transformações do ser. Um ser e um não-ser que encontram no movimento do ente, a sua espacialidade de ordem qualitativa. Do em-si mediante o outro, coexistindo, o ser mantém em si a natureza diversa da relação, numa ordem múltipla de ligações e relações. Essa multiplicidade em suas determinações de caráter diverso, em intensidade e qualidade, remete enfim a ordem do real, ou seja, a sua escala: uma hierarquia diferencial de relações entre entes e entre partes do todo que coexistem em diferentes níveis.

Dizer da parte, ou de um ente determinado, como assinalado anteriormente, impõe a necessidade de falar mediante o todo, vale dizer de suas ligações/relações com o resto, ou seja, de sua inserção escalar. Mas um ente em-si é um todo, ou seja, coexistência reativa de partes constituintes deste ente. 
Uma parte que em-si mesma se faz identidade particular contínua, quando compuser a descontinuidade de uma totalidade maior. A cada elemento será dito: será parte, portanto um dado contínuo, mas será em-si mesmo todo, e assim será dotado de descontinuidades. Em-si é descontínuo, posto que como todo é constituída de partes distintas. Mas, de outro lado, é em-si contínua mediante outra unidade contínua, sua alteridade. Assim, na escalaridade das relações de coexistência entre entes, entre todo e parte, o espaço será contínuo e descontínuo.

Nessa trama de relações, nessa estrutura de determinações, nesse horizonte de coexistências entre as partes, entre parte e todo, localizar-se implicará distanciar-se. Mas observe-se que é a natureza qualitativa da relação que determinará a distância.

Por exemplo, ao observamos que uma cidade A se encontra estreitamente vinculada a uma cidade $\mathrm{B}$ por diferentes meios de comunicação, poderá estar mais próxima de outra cidade $\mathrm{C}$ onde tais relações não são tão intensas. Esse exemplo permite ver as duas possíveis noções de espaço: numa suposição, A e B estão a mil km, e A e C estão a 200 km. Do ponto de vista cartesiano, A e C estão mais próximas, e isso se sustenta pela perspectiva do espaço absoluto (é o cenário de Newton), e o fundamento é a quantidade. Porém, na perspectiva que anunciamos, ampliando a significação de espaço relativo de Leibniz, a distância menor é entre $A$ e B, se entre $\mathrm{A}$ e $\mathrm{B}$ existir intensa relação de comunicação, maior que a relação de $\mathrm{A}$ com $\mathrm{C}$. $O$ fundamento agora não é a quantidade (a distância em quilômetros), mas a qualidade.

Das distâncias guardadas entre as várias partes, ter-se-á a extensão. E da extensão poderá ser dito quanto a sua densidade, maior ou menor, no tocante à intensidade das relações/ determinação entre as partes. Eis os princípios geográficos: localização, distribuição, distância, extensão, densidade e escala.

Pelo conjunto desses princípios, identificamos o território. Surge a forma determinada pela apropriação da natureza pela sociedade. No território está consolidada a ordem tópica agora tomada em seus aspectos qualitativos, que vemos na distribuição dos entes, em suas distâncias, densidade, extensão e escala. Ou seja, no contexto de uma duração, o território responde pela estrutura proveniente das relações entre os entes geográficos em coexistência. De como se configura o território a partir dos princípios geográficos, teremos o caráter da espacialidade. Assim, da reunião desses princípios geográficos, teremos a natureza do espaço de cada parte, e, de cada parte em relação às outras, a espacialidade do todo.

Agora, se tomarmos isso tudo por sua apreensão imediata, podemos proceder a uma classificação do visível. Podemos the conferir uma geometria, mediante um espaço de natureza quantitativa. Podemos obedecer a princípios geográficos de localização, distância, extensão, densidade, delimitação, altura, largura, numa leitura quantitativa. Podemos observar isso numa hierarquia escalar numérica e traçar um desenho do visível. Ou simplesmente podemos observar fenômenos como fluxos, por exemplo, e por fim descrevê-los. Nessa, descrição observamos sua presença, orientados pela observação dos fenômenos imediatamente percebidos. Com isso, pomos em destaque a percepção do observado. E nisso podemos constituir a Paisagem. Na verdade, essa dimensão tem um caráter fundamental: a dimensão empírico-imediata dos entes que compõe a geografia. Portanto, a Paisagem é a categoria que consagra o fenomênico da geografia. 
Mas a Paisagem também pode ser tomada do ponto de vista qualitativo, quando consideramos o papel da percepção na relação sociedade-natureza, sobretudo na relação homem-meio. Entretanto, ela levará à suposição de outra categoria geográfica, como veremos adiante.

Por ora, retomemos a linha do afirmado. Do ponto de vista qualitativo, localizar e distribuir significa identificar a trama de relações que definem a localização. $\bigcirc$ "estar" é definido pela posição na trama, a que relações o objeto geográfico localizado estabelece. Por isso, a perspectiva a seguir é a do espaço relativo.

Portanto, no territorializar, ou seja, a configuração dos princípios no constituinte de uma geografia determinada tem em si aspectos não só quantitativos, mas também aspectos qualitativos de relevância superior. Muito mais que metrificação quantitativa, os princípios levam em si sentidos qualitativos, que vão variar com a dimensão escalar.

Podemos, enfim, ter que uma determinada territorialização dos princípios geográficos em seu conjunto de aspectos qualitativos e quantitativos -, definem em síntese uma organização espacial respectiva. Em resumo: a organização espacial, revelada pela ordem do território, é a síntese dos aspectos qualitativos/quantitativos, dos assim chamados princípios geográficos.

Vale ainda o comentário de que o território, como categoria da ciência geográfica, tem sua tradição firmada pela geografia política. A soberania de um Estado-nação teria uma dimensão geográfica correspondente ao território delimitado por fronteiras ou limites. Ou seja, nos termos da tradição da geografia política, um povo se apropria da natureza definindo seu território. Subjaz aqui o sentido de poder exercido sobre o território. Há um claro viés político, mas ele não se daria sem um fundamento no econômico, mesmo que recorrêssemos ao fundamento precário do malthusianismo subjacente à geografia política tradicional.

De todo modo, dessa tradição ficou associado ao território o sentido de apropriação. Porém, ressalte-se: não devemos confundir o território com os próprios entes nele presentes. É sua coexistência, posta por uma organização espacial definida pelos princípios geográficos, que faz surgir o território. É a estrutura aí definida que nos aproxima desta categoria.

A partir dessas considerações acerca do território, chegamos a outro problema, presente na relação sociedade-natureza. Como visto, o político implicou a suposição do econômico. Diante disso, temos dois aspectos a considerar:

a. A relação sociedade-natureza, ou mesmo a relação homem-meio, permite ser vista sob que matizes? Vimos acima o político e a necessidade do econômico. Mas que outros aspectos poderiam ser citados? Relação de identidade e pertencimento, por exemplo. Pode-se afirmar que, quando colocamos em perspectiva a relação sociedade-natureza e a relação homem-meio, nada escapa a essa relação. Quando afirmamos que nada escapa, nos referimos àquilo que por vezes é tratado de forma temática por uma determinada disciplina científica. Centrar, portanto, a reflexão a partir da relação significa pôr em questão a totalidade e como isso é tratado pelo saber disciplinar. Como a geografia aqui não está sendo tratada como um desses ramos disciplinares, ela, assim como a história, implica essa perspectiva de inter-relação entre partes e, portanto, devem-se considerar todos os tipos de relação. 
b. Uma vez identificados esses matizes, eles ocorreriam de intensidade e forma homogênea na definição de todo o território? Se sim, não seria necessário outras categorias, e toda a geografia do mundo poderia ser entendida com estas três categorias tópicas; o espaço, a paisagem e o território, tanto quanto no que diz respeito ao tempo nos deteríamos apenas na duração. E tudo isto seria a organização espacial tomada em sua continuidade.

Porém isso não ocorre. A têmporo-espacialidade que constitui a geografia do mundo é intensamente descontínua. Tanto quanto a relação sociedade-natureza e a relação homem-meio se dão numa unicidade.

Em verdade, tudo poderia ser sintetizado na definição de existência. Existir significa se relacionar. E relacionar-se significa fazê-lo em termos sociais num processo que envolve uma dupla complementar e simultânea apropriação: apropriação objetiva e subjetiva. A existência de cada indivíduo se dá socialmente como sujeito histórico e geográfico. Essa condição de sujeito de cada indivíduo representa sua inserção social, ainda que a ela não se reduza. Como diz Emma Goldman (1986, p. 13/14) "o indivíduo é a verdadeira realidade da vida, um universo em si próprio", ou "o homem vivo não pode ser definido, ele é fonte de toda a vida e de todos os valores, ele não é parte disto ou daquilo; ele é um todo". Que indivíduo algum possa ser entendido sem sua condição de sujeito, ou seja, como ente social, não resta dúvida, mas há mais que isso. E a geografia é para o indivíduo sua condição de existir, o que equivale a dizer que a geografia representa a totalidade desse existir. E do indivíduo à sociedade, passando pela condição de sujeito, e sua (eventual) condição de classe, a relação sociedade-natureza se realiza nessa totalidade una, em escala distintas e, sobretudo, de uma geografia descontínua. Resta dar sequência à explicitação das categorias geográficas que permitem dar conta desse complexo, descontínuo e inter-relacionado, constituído por uma universalidade, e sua realização particular mediante injunções singulares.

Universal, particular, singular. Essa famosa tríade que emerge do campo da lógica tem que ter sua origem na constituição da realidade objetiva. Quando supomos o homem como sujeito, o tomamos em sua inserção naquilo que é universal a todos os membros de uma formação, que podem ser, por exemplo, as formas de reprodução material dessa sociedade. No caso desse exemplo, identificamos as determinações objetivas de como a sociabilidade é constituída, e é aí que cada indivíduo se insere respondendo de forma particular. Trata-se da divisão do trabalho, das relações sociais de produção, a constituição de classes e frações de classe, enfim, o conjunto das forças produtivas com suas características próprias.

Por esse mesmo caminho, devemos entender a geografia produzida. Há um contexto universal, fruto do como se define a reprodução material da sociedade (que é a forma dominante de apropriação da natureza) e como ela pode ser observada em sua realização particular. A geografia objetivada representa um devir histórico determinado. Por essa razão devemos ver o território em suas especificidades, ou seja, nos seus lugares determinados. Isso define onde e por que os entes estão onde estão, ou seja, a localização e a distribuição. 
Ou, por outra, podemos observar a localização de determinado conjunto de entes, definindo assim uma ordem de distribuição. Nesse contexto de distribuição, observamos a relação entre esses entes; afinal o que está localizado está sempre localizado em relação a outros entes. Temos aí um determinado território. Se impõe a indagação do porque a distribuição tem esse perfil, que por sua vez caracteriza a relação espacial entre os entes. É aqui que temos que voltar a relação sociedade-natureza, e observar como ela define esta estrutura. Porém, dependendo da escala que observamos, mesmo tendo em conta que a relação sociedade-natureza em seus elementos universais seja a mesma, temos, muitas vezes, que ao território definido se mostra descontínuo.

Assim, podem interagir ordens distintas na definição da localização e, portanto, da distribuição. Numa ordem hegemônica e universal, uma territorialidade é posta mediante outra de caráter próprio definido por uma história singular. A singularidade fará a universalidade existir de uma determinada maneira específica, do mesmo modo que permitirá territorializar-se de maneira particular. A singularidade rompe a continuidade. A escalaridade que vislumbra os muitos e distintos territórios particulares.

Parece difícil falar dessa relação sociedade-natureza quando o que caracteriza a realidade de forma predominante é a geografia urbana, como afirmamos em nota, páginas atrás. Especialmente nos dias atuais, quando acumulação via especulação financeira se tornou central, ou seja, quando a moeda se torna um fim em si e é capaz de se reproduzir de forma autônoma. Mas é exatamente por esse motivo que insistimos nessa relação. Toda geografia produzida representa, entre outros aspectos, a infraestrutura necessária para à reprodução material da sociedade, e no nosso caso uma reprodução baseada na exploração do homem por outro, numa realidade ancorada na acumulação da moeda, na reprodução do dinheiro e subordinação da produção a essa lógica financeira especulativa. Por mais que o crescimento do capital especulativo possa ser (e é) superior ao capital produtivo (e isso já é em si um problema), o primeiro nunca é independente do segundo. Ou seja, sem a produção material, o fundamento do econômico se esvanece na virtualidade especulativa da moeda. Portanto, a relação sociedade-natureza nunca se extingue, pois é onde está a raiz última da produção.

Feita essa breve ressalva, temos agora que aperfeiçoar nossa proposição anterior dizendo: podemos deduzir que a organização espacial é a sintese particular (sintese do universal com o singular) dos princípios geográficos em seus aspectos qualitativos/quantitativos de um dado LUGAR. A geografia de um lugar responde por sua história na conjuntura atual, presente, quando os elementos contingentes, singulares penetram na essência das relações entre os entes que coexistem, fundindo-se com o que é dado necessário nessas relações. Ou, como diz Pierre George (1978, p. 110):

Mas a geografia tem outras preocupações: em primeiro lugar, a de integrar em toda visão teórica e elaborada que leve a uma utilização ótima de um espaço reduzido a um número determinado de componentes (ainda que este número seja elevado) todas as rugosidades suscetíveis de comprometer o modelo, assim como a variedade do meio natural tanto no espaço como no tempo (problema de ritmos e variações) em escala inter-regional, e todo o efeito estático e dinâmico, de 
qualquer sentido, proveniente do legado de gerações precedentes, tanto na área do equipamento concreto como na das ações irreversíveis e nas mentalidades.

Escrito originalmente em 1970, esse texto traz essa relação entre o universal (no caso de Pierre George, o modelo) e a singularidade (as rugosidades), assim como leva em conta a escala e o tempo.

E nessa perspectiva insere-se o tempo; o tempo encontra no lugar sua condição específica, em plena identidade com o espaço, como duração. A ordem definida pelo território dura.

E a duração significa a hierarquia de ritmos. E os ritmos estão ligados à frequência das relações, quando estão organizadas em ciclos. Tais ritmos, em desigual proporção quanto a seu grau de determinação, encontram uma específica territorialidade. Ou seja, o tempo resultará da identidade imediata com uma particular síntese dos princípios geográficos, uma territorialidade particular. Isto é, uma dada organização espacial, em que uma suposta alteração qualitativo/ quantitativa dessa síntese supõe sucessão, a negação da duração, a ruptura da hierarquia dos ritmos, a afirmação do tempo pela realização do movimento. Encontramos aqui o tempo geográfico (ou o tempo do geográfico). Isso significa reestruturar as relações entre os entes geográficos, implicando não só a modificação do ser de cada um, mas também a supressão eventual de algum deles dentro da ordem das coexistências. Tudo isso se dá de forma desigual entre os objetos.

Mas os lugares são muitos. São territorialidades de especificidades particulares. São escalarmente distintos. São instâncias em níveis diferentes de relações das partes que coabitam. São patamares de determinação na geograficidade contínua/descontínua do mundo. Os lugares que são a territorialidade da singularidade identificada na sua existência mediante a universalidade. Cada lugar tem seus ritmos, portanto, sua temporalidade na identidade com a territorialidade das relações entre as partes nesse todo que é o lugar. Assim, podem ter conteúdo conceitual distinto. Os lugares são "os espaços de conceituações diferentes" (Lacoste, 1988, p. 67-68).

Eis as dimensões escalares que comporão a trama estrutural da realidade, que se revelam pela intensidade variável de determinações de um(ns) aspecto(s) singular(es). É aqui que a totalidade como pressuposto epistemológico ganha seu significado profundo. Tomada na perspectiva da geografia, ou seja, mediante a consideração de sua geografia, a realidade do mundo será compreendida na inteireza de suas relações mediadoras e fundantes. Afinal escala é um conceito que sempre tem como referência o todo em seu "tamanho real". Portanto, articular a compreensão da realidade a partir da perspectiva escalar é estar sempre em sintonia com a complexa totalidade na qual estamos mergulhados. Pensar escalarmente é o pensar totalizante em geografia. Superando a impermeabilidade das divisões formais no campo das disciplinas científicas, uma vez que a geografia é categoria da existência em sua complexidade, a geografia é condição universal de todos os entes que existem. ${ }^{4}$

Eis o profundo significado da Geografia. $\bigcirc$ homem, como indivíduo, como sujeito, é desde sempre radicalmente mundo em sua constituição ontológica. $\bigcirc$ mundo do homem é em sua constituição caracterizado pela história e pela geografia. $\bigcirc$ universal concreto (essência),

4 "En suma, la totalidad es la articulación dinámica de los processos reales caracterizada por sus dinamismos, ritmos temporales y despligues espaciales, y esta articulación puede concretarse en diferentes recortes del desarrollo histórico" (Zemelman, 1992, p. 68, grifo nosso). 
aquela essência presente em todas as relações, se define em função de uma história e uma geografia. $\bigcirc$ mundo é revelado em todas as suas dimensões, em seus ritmos, na duração da relação entre suas partes, relações que fundam sua essencialidade na hierarquia escalar das codeterminações, na estrutura lógica de seu movimento. A geografia desvela a natureza ontológica última do ser do homem no mundo. Ou seja, a oportunidade de por o caráter de nossa existência em questão. Espaço e tempo como categorias íntimas da existência dos entes. Eis a medida da reflexão possível e necessária.

Os lugares escalarmente se postam. Suas conceituações se definem na medida de suas singularidades. Observe-se que se tomarmos a paisagem pelo viés qualitativo, ou seja, se nos determos no conteúdo em-si do ato perceptivo, teremos outra dimensão a considerar. A percepção é individual, é do indivíduo, e, assim, teremos que considerar a paisagem numa dimensão do vivido pelo indivíduo. Podemos falar nesse caso, por exemplo, de identidade e pertencimento a determinados lugares, e todos os problemas decorrentes disto, como a questão da legitimidade dessas relações.

Se nos fixamos nas dimensões do indivíduo, teremos pela frente o seu espaço de vida. Temos aí um conjunto de aspectos que se revelam numa territorialidade específica. É a órbita do mundo cotidiano, da cotidianeidade. Espaço vivido, ou espaço de vida, territorialização das singularidades próprias da vida cotidiana, onde o aleatório está na individualidade do indivíduo. Simbiose imediata com o meio ambiente que nos cerca. Enfim: o habitat. Ou, nas palavras de Agnes Heller (1987, p. 382, grifos do original):

El contacto cotidiano tiene siempre su espacio peculiar. Este espacio es antropocéntrico: en su centro está siempre un hombre que vive su vida cotidiana. Su articulación está siempre fijada por la vida cotidiana, donde la experiencia interior espacial y la representación del espacio están indisolublemente interrelacionados.

Confluência do universo íntimo, subjetivo, com a generalidade social, da vida em sociedade, que se traduz na perspectiva individual, no repetir do corriqueiro da rotina. $\bigcirc$ habitat. Lugar de heterogeneidade, onde a vida se afigura em heterogeneidades, sedimentando objetivações do ente social. Território onde se afiguram o trabalho, interações, vida pública, vida privada.

Um dos aspectos que singulariza o habitat, e talvez o principal, é a imediaticidade. $\bigcirc$ aspecto espontâneo e automático com o qual nos pomos no suceder das horas do dia. Aqui, o individual transitará no espaço de vida percebendo espontânea e imediatamente a paisagem que o cerca. Portanto, aqui, a paisagem aparece como um componente de construção subjetiva na geografia do indivíduo. Nessa dimensão escalar, todo tipo de emoções e sentimentos está em duelo com determinações "exteriores" ao indivíduo. $\bigcirc$ duelo dessas determinações é a vida privada de cada um. A universalidade imposta pelas formas de produção material da sociedade estabelece o caminho do processo de individuação (formação do indivíduo). A reposta de cada um a essa condição geral está relacionada a nossas iniciativas de sobrevivência. Já a existência (que é de cada um) é uma reposta particular a esse condicionamento geral. A existência é processo de subjetivação do mundo que tem por base a sobrevivência e suas determinações 
objetivas. Uma paisagem em que a percepção muitas vezes se distancia da realidade objetiva e suas dinâmicas, um espaço de vida descontínuo, sem lógica aparente de inter-relações.

Nessa dimensão da observação, é fundamental não destacar os elementos da percepção. Um diálogo com a fenomenologia aqui é possível, ainda que o observado não se reduza ao percebido. $\bigcirc$ mesmo podemos com relação à semiótica, permitindo pensar uma semiótica da paisagem. Pela imediaticidade do percebido, aqui a paisagem se revela como signo. ${ }^{5}$

A paisagem é o significante. Da linguagem à consciência, de sua inserção na geografia que o cerca, o indivíduo funda o significado da existência calcado na empiricidade do imediato, na suposição mítica/mística dos lugares. É exatamente nesse empírico em que a paisagem é o significante que se desenha o universo do percebido. É nessa dimensão de significantes que se inscrevem as mentalidades. Na condição imediata do ato, o indivíduo expressa a suposição de sua existência.

Num ambiente onde as práticas se mostram predominantemente como um pragmatismo aparentemente espontâneo, a relação significante-significado se metamorfoseia de signo em fetiche.

A anulação, a superação do mundo cotidiano em sua realização territorial é impossível. Ónico atenuante são atitudes de "suspensão momentânea" no suceder da rotina como, por exemplo, pelo trabalho artístico ou científico:

Ora, o acesso à consciência humano-genérica não se realiza neste comportamento: só se dá quando o indivíduo pode superar a singularidade, quando ascende ao comportamento no qual joga não todas as suas forças, mas toda a sua força numa objetivação duradoura (menos instrumental, menos imediata) [...]. Nesta suspensão (da heterogeneidade) da cotidianeidade, o indivíduo se instaura como particularidade, espaço de mediação entre o singular e o universal, e comporta-se como inteiramente homem (Paulo Netto; Carvalho, 1987, p. 68, grifo do original).

Habitat, portanto, seria o lugar da realização imediata do cotidiano do indivíduo, onde as coisas são naturalizadas mediante ideologias, onde também sofremos uma ordenação disciplinar decorrente de ingerências jurídico-políticas e onde a estética da paisagem não é destituída de significados. ${ }^{6}$

E, finalmente, devemos observar o indivíduo, como sujeito, nos termos do econômico, como integrante do conjunto das forças produtivas. $O$ indivíduo convertido em força de trabalho. E, neste ponto, o indivíduo é remetido, junto com seu espaço de vida, a compor uma

5 "Tanto faz; a apropriação de uma topia só é possível postulando uma heterotopia: é só a partir deste movimento que um discurso sobre o espaço pode instituir-se. Porque o espaço assim instaurado nada mais é que um significante; ele está aí apenas para ser assumido e significa coisa diferente do espaço, isto é, o homem que é o significado de todas as linguagens" (Greimas, 1976, p. 115-116, grifos do original).

6 "Caso ainda mais altamente significativo é o da arquitetura que comporta uma prática específica, parcial e especializada, ligada ao quotidiano. A orientação social impõe ao arquiteto a realização de espaços que convenham à sociedade, quer dizer, que "reflitam" as suas relações, dissimulando-as se possível (se não for muito oneroso) na paisagem. A arquitetura oscila entre o esplendor monumental e o cinismo do habitat [grifo do original]. No monumental, tanto o que se pede emprestado aos estilos do passado quanto as exibições de tecnicidade procuram dissimular o sentido, mas só o conseguem ostentar ainda mais: os monumentos são os lugares do Poder, as sedes oficiais, os locais em que ele se concentra, se reflete em si próprio, o lugar onde ele olha de alto e onde transparece" (Lefebvre, 1988, p. 250, grifos nossos). 
espacialidade de escala distinta. Localizar-se agora significa pertencer à trama de relações constituída pela distribuição das forças produtivas em geral.

Da geografia industrial, da geografia da circulação, a geografia agrária, a tensão entre geografia do urbano e geografia do rural, a rede (distribuição) de cidades e sua hierarquia medida pelo fenômeno dos fluxos, as cidades e seu hinterland, a relação campo-cidade, a territorialização do ritmo da produção no contexto da formação econômico social, enfim, a Geografia desenha-se agora em Regiões.

A Região remete à singularização de aspectos característicos, especialmente na natureza do processo produtivo. Ou mais claramente, a caracterização advinda do complexo de relações sociais de produção. Portanto, a constituição histórica das formações econômico-sociais acaba por constituir especificidades territoriais que se singularizam em sua estrutura específica de relações sociais de produção, caracterizando com isso a Região.

Quanto à paisagem em relação à região, nesse caso se configurará como a parte visível de um território respectivo a cada região. $\bigcirc$ aspecto empírico tradicional presente na paisagem permite ver o complexo de relações fundantes do território. Fluxos de capitais, de mercadorias, de informação, de força de trabalho, são os aspectos fenomênicos dessa Geografia Regional. Porém, em essência, está a relação sociedade-natureza, tomada aqui numa perspectiva escalar que envolve rede de cidades, e estas redes com suas respectivas relações campo-cidade. A região deve ser tomada numa totalidade, nos termos do econômico, articulando o contexto da divisão do trabalho. Do posseiro ao operário metalúrgico, da mão de obra familiar ao tratorista na agricultura de precisão, do trabalhador temporário na agricultura aos assalariados no chamado "setor de serviços". Todos são atores geográficos.

Dito isto, ficamos à vontade para dar esse caráter objetivo à região, como descontinuidade que tem determinada singularidade, remetendo a um patamar escalar específico. Singularidade esta, como afirmado, em estreita relação com o econômico. Articulam-se consumo, troca, circulação, a partir do que é ensejado ao nível da produção. As articulações históricas entre o espaço urbano - este como continuidade qualitativa centrada no ritmo do processo produtivo da indústria - e o espaço agrário - continuidade singularizada pela dispersão (extensão) própria da produção agropecuária, onde a renda da terra é elemento determinante fundamental na geografia do campo, juntamente com as lutas sociais ali ensejadas - configuram-se regionalmente a partir das articulações postas nas relações sociais de produção. Pelo desdobramento, portanto, da máxima "desenvolvimento desigual e combinado", a região é uma categoria fundamental na caracterização da geografia.

Não poderíamos concluir sem falar em identidades regionais. $\bigcirc$ processo geográfico se caracteriza pela passagem do rural ao urbano, transformando campo e cidade, a geografia industrial e a geografia agrária. Pode-se dizer que, quando a geografia do rural era hegemônica sobre a geografia do urbano, era possível encontrar culturas regionais, e, portanto, identidades regionais. A hegemonização da geografia do urbano sobre a geografia do rural representa a descaracterização do fundamento objetivo dessas culturas regionais, convertendo-as em "tradição". A geografia do urbano é marcada pela dissolução destas identidades de origem. Nesse contexto, abre-se o debate sobre o caráter e a legitimidade dessas identidades regionais. 
Em plena hegemonia do urbano sobre o rural e suas respectivas geografias, como pensar tais identidades de caráter regional. Culturas de um passado rural são revividas e re-significadas, retiradas de seu contexto original e experimentadas dentro da geografia urbana. Não seria demais lembrar que, nesse novo contexto, tais referências identitárias ganham também um mercado de consumo específico, fazem parte de uma indústria cultural.

Dito tudo isso, portanto, acerca das categorias do discurso geográfico, fica eliminada a predominância exclusiva do arcabouço lógico formal de considerar o espaço como universal, onde este contém o particular, ou seja, o lugar. E este último por sua vez contém a área, a região, o território, ou seja, a dimensão singular, como nos dizia Silva.

Para as ingerências de ordem qualitativa, estas que envolvem o conteúdo, na sua composição com o necessário (o universal) e o contingente (o singular), a lógica é outra. O lugar é a territorialidade da síntese entre o universal e o singular. A singularidade caracterizará a particularidade do Lugar através do universal. Singularidade é contingente, e assim como o universal, deve ser identificado na relação entre sociedade e natureza, entre homem e meio.

Portanto, o Lugar é a dimensão universal do espaço que é posta pela singularidade própria de cada Lugar particular. Ali, as ingerências universais encontram sua espacialidade, mas isto nos é dado pela singularidade. O Lugar é o todo; a síntese entre o universal e o particular.

E o Lugar poderá ser Região, ou poderá ser habitat, e tantos outros espaços de conceituações diferentes como territorialidades de singularidades distintas encontradas no mundo. $\mathrm{Na}$ escalaridade diferencial entre os lugares, entrecruzam-se regiões, habitats, as dimensões espaciais do urbano e do industrial, como resultado de uma territorialidade de elementos necessários. Estes, que se medeiam pelas contingências. Geografia de uma diversidade, numa espacialidade descontínua de lugares. Os lugares que são o todo, mas que de todo poderá ser parte e de particular se converterá em universal. A escalaridade muda, a perspectiva de análise se aprofunda, novas totalidades emergem, inéditas contingências singulares são vistas nesta nova dimensão escalar da universalidade.

\section{Considerações finais}

Ser é pertencer. Estar situado. Ser de um ente constituído (constitutivo) de uma geograficidade. ${ }^{?}$

Fizemos uma distinção aqui entre geografia e o procedimento que tenta dar conta dessa característica da realidade, ou seja, a ciência geográfica. Este texto falou das duas coisas. O impasse aristotélico-kantiano, referido por Silva Correa da Silva diz respeito propriamente à ciência. Obviamente, isso representava um esquema lógico de pensamento, que em muitas medidas revela a forma pela qual essa ciência pensa a geografia do mundo. Talvez os propósitos da ciência geográfica, conscientes ou não, tenham definido esse parâmetro teórico.

Nossa meta aqui foi apresentar uma nova posição. Mas o fizemos não olhando exclusivamente para a ciência (mas mantendo com ela um diálogo crítico). $\bigcirc$ que se fez foi indagar o que é a geografia como dado constituinte do real. Os propósitos referidos acima levaram a práticas

7 O emprego desse conceito - geograficidade - não está baseado nas concepções de Éric Dardel. Portanto, ainda que haja possibilidade de diálogo com esse autor, acreditamos fundar a geograficidade sobre outras bases. Por essa razão, escolhemos dizer geográfico, e não geograficidade, no título deste trabalho. 
científicas um tanto heterogêneas, razão pela qual indagar o que é geografia, tendo em mente a ciência geográfica, é cair numa tautologia esquizofrênica. Um pensamento que tenta responder por si mesmo, remetendo a respostas totalmente distintas.

Fomos buscar o que é geografia como dado constitutivo da realidade na própria realidade. Algo que diz que se localizar não é algo fortuito. Estar é propriedade das coisas que existem. A referida relação entre ser e estar. É nesse sentido que espaço e tempo são categorias. É nessa direção que espaço e tempo são categorias da existência dos entes no mundo. E existir é ser que passa por estar como ente. Somos o que somos por estarmos aqui neste momento. Afirmação singela, mas efetivamente fundamental. Somos o que somos por ter essa condição geográfica do existir. Eis a Geografia do real como dado constitutivo deste.

Observada a tradição do pensamento geográfico, vê-se que a razão da persistência do impasse aristotélico-kantiano está exatamente em tomar o espaço exclusivamente do ponto de vista quantitativo, mesmo que a intenção não seja essa. $\bigcirc$ esquema lógico decorrente dessa posição acerca do espaço, como categoria ligada à quantidade, é coerentemente articulado com a lógica formal.

Portanto, a ruptura começa no momento em que tomamos a qualidade como referência. Entretanto, a qualidade do ente decorre de determinações produzidas por múltiplas relações. E isso em termos de espaço e tempo. As qualidades fenomênicas do real são na verdade demonstrações empíricas de um dado efetivo que subjaz a essa perspectiva imediata.

A ciência geográfica, portanto, será a demonstração da diferença de ritmos em durações distintas, tensionando em diferentes níveis a sucessão. É a territorialidade contínua/descontínua na identidade/diferença dos ritmos e durações.

Assim, a ciência geográfica é o estudo desse movimento do real pela perspectiva de sua têmporo-espacialidade. Tomada assim, tem o compromisso com o todo. Porque tem em mente a qualidade e as diferentes relações entre os entes. A composição múltipla das determinações estabelecidas nas relações fundantes do ser do ente.

A ciência geográfica pode se abrir a uma dimensão mais ampla e essencial nas suas considerações. Ou seja, há ligação uma estreita e fundamental entre o existir e a condição geográfica desse ato. Com isso, pensar a geografia é pensar a condição (qualidade) da existência do homem. Permite ver por onde passa a possibilidade da plenitude do ser.

\section{Referências}

ANDRADE, A. As duas faces do tempo. São Paulo: José Olímpio/Edusp, 1971.

BESSE, J.-M. Ver a Terra. São Paulo: Perspectiva, 2006.

BRANCO, J. M. Dialética, ciência e natureza. Lisboa: Caminho, 1989.

GEORGE, P. Os métodos da geografia. São Paulo: Difel, 1978.

GOLDMAN, E. O indivíduo na sociedade. Lisboa: Coletivo Maquinetas, 1986.

GREIMAS, A. J. Semiótica e ciências sociais. São Paulo: Cultrix, 1976.

HEGEL, G. W. F. Enciclopédia das Ciências Filosóficas: a ciência da lógica. São Paulo: Loyola, 1995. v. 1. 
HEIDEGGER, M. Ontologia: hermenêutica da facticidade. São Paulo: Vozes, 2012.

HELLER, A. Sociología de la vida cotidiana. 2. ed. Barcelona: Península, 1987.

INWOOD, M. Dicionário Hegel. Rio de Janeiro: Jorge Zahar, 1997.

LACOSTE, Y. A geografia: isso serve, em primeiro lugar, para fazer a guerra. Campinas: Papirus, 1988.

LEFEBVRE, H. Estrutura social: a reprodução das relações sociais. In: FORACCHI, M.

M.; MARTINS, J. S. (Org.). Sociologia e sociedade. 13. ed. Rio de Janeiro: Livros Técnicos e Científicos, 1988. p. 219-254.

LEIBNIZ, G. A monadologia, discurso de metafísica e outros textos. 2. ed. São Paulo: Abril Cultural, 1983. (Coleção Os Pensadores.)

MARTINS, E. R. As dimensões do geográfico: diálogo com Armando Corrêa da Silva. Geousp Espaço e Tempo (Online), São Paulo, v. 18, n. 1, p. 40-54, 2014.

MARX, K. Manuscritos económico-filosóficos. Lisboa: Edições 70, 1989.

MARX, K. Para a crítica da economia política. São Paulo: Nova Cultural, 1987. v. 1. (Coleção Os Pensadores.)

MENDOZA, J. G.; JIMÉNEZ; J. M.; CANTERO, N. O. El pensamiento geográfico. Madrid: Alianza, 1982.

MOREIRA, R. Pensar e ser em geografia. São Paulo: Contexto, 2007.

PAULO NETTO, J. P.; CARVALHO, M. C. B. Cotidiano: conhecimento e crítica. São Paulo: Cortez, 1987.

SANTOS, M. A natureza do espaço. São Paulo: Hucitec, 1996.

SILVA, A. C. As categorias como fundamentos do conhecimento geográfico. In: SANTOS, M. O espaço interdisciplinar, São Paulo: Nobel, 1986a. p. 25-37.

SILVA, A. C. De quem é o pedaço? São Paulo: Hucitec, 1986b.

SILVA, A. C. O conceito de espaço de David Harvey: implicações ontometodológicas. In: SILVA, A. C. De quem é o pedaço? São Paulo: Hucitec, 1986c. p. 91-97.

SILVA, A. C. O espaço como ser: uma auto-avaliação crítica. In: MOREIRA, R. Geografia: teoria e crítica. Petrópolis, RJ: Vozes, 1982. p. 75-92.

SILVA, A. C. O espaço fora do lugar. São Paulo: Hucitec, 1978.

SORRE, M. Rencontres de la géographie et de la sociologie. Paris: Marcel Rivière, 1957.

TROLL, C. El paisaje geográfico y su investigación. In: MENDOZA, J. G.; JIMÉNEZ, J. M.; CANTERO, N. O. E1 pensamiento geográfico. Madrid: Alianza, 1982. p. 323-329. ZEMELMAN, H. Los horizontes de la razón. Barcelona: Anthropos/El Colegio del México, 1992. v. 1. 